\title{
The effect of acute ophiobolin A treatment on HO-mediated inflammatory processes
}

Human and Experimental Toxicology

$$
\begin{array}{r}
\text { C The Author(s) } 2016 \\
\text { Reprints and permission: } \\
\text { sagepub.co.uk/journalsPermissions.nav } \\
\text { DOI: } 10.1 \text { I 77/0960327II6658I07 } \\
\text { het.sagepub.com } \\
\text { SAGE }
\end{array}
$$

\author{
Anikó Pósa', Renáta Szabó', Zita Szalai', Krisztina Kupai', \\ Zoltán Deim', Zsolt Murlasits², Ottó Bencsik ${ }^{3}$, \\ András Szekeres ${ }^{3}$, Csaba Vágvölgyi ${ }^{3}$, László Balogh ${ }^{4}$, \\ Béla Juhász ${ }^{5}$, Zoltán Szilvássy ${ }^{5}$ and Csaba Varga'
}

\begin{abstract}
Many microbial and plant-derived metabolites contribute to the production of inflammatory mediators and the expression of pro-inflammatory molecules. Ophiobolin A (OPA) is a fungal secondary metabolite produced by Bipolaris species. The aim of our study was to examine the acute effects of this compound on inflammatory processes.

Male Wistar rats were treated with $5 \%$ ethanol, $0.01 \mathrm{mg} / \mathrm{kg}$ OPA, $0.1 \mathrm{mg} / \mathrm{kg}$ OPA and $1.0 \mathrm{mg} / \mathrm{kg}$ OPA per os. After $24 \mathrm{~h}$ of the administrations, inflammatory mediators such as interleukin-6 (IL-6), tumour necrosis factoralpha (TNF- $\alpha$ ) and myeloperoxidase (MPO) enzyme as well as heme oxygenase $(\mathrm{HO})$ activity were measured in both plasma and cardiac tissue, along with serum alanine aminotransferase (ALT) and aspartate aminotransferase (AST). We found that OPA caused a significant elevation in the concentrations of IL- 6 and TNF- $\alpha$, increased MPO activity and decreased $\mathrm{HO}$ enzyme activity in the plasma. While OPA induces inflammation in the plasma, it did not change the level of inflammatory mediators in the cardiac tissue and the concentrations of serum ALT and AST. Our findings indicate that rapid release of inflammatory mediators by OPA promotes systemic inflammation. However, this acute OPA treatment does not show toxic effects on the cardiac tissue and the concentrations of liver enzymes.
\end{abstract}

\section{Keywords}

Ophiobolin A (OPA), inflammation, pro-inflammatory cytokines, myeloperoxidase, heme oxygenase

\section{Introduction}

Inflammation is a complex set of interactions among soluble factors (cytokines) and cells that can arise in both tissue and plasma in response to infectious, toxic or traumatic injury. ${ }^{1,2}$ The pro-inflammatory cytokines, such as tumour necrosis factor-alpha (TNF- $\alpha$ ), interleukin-1-beta (IL-1 $\beta$ ) and IL-6, are involved in the initiation and amplification of the inflammatory process. TNF- $\alpha$ and IL- $1 \beta$ act in synergy to enhance IL-6 secretion and may significantly contribute to the overall systemic inflammation. ${ }^{3}$ Along with the effects of cytokines, myeloperoxidase (MPO) activity, which synthesized and secreted by neutrophils, is determined as an inflammatory biomarker. The plasma or tissue concentrations of MPO are markers
'Department of Physiology, Anatomy and Neuroscience, Faculty of Science and Informatics, University of Szeged, Szeged, Hungary ${ }^{2}$ College of Arts and Sciences, Qatar University, Qatar

${ }^{3}$ Department of Microbiology, Faculty of Science and Informatics, University of Szeged, Szeged, Hungary

${ }^{4}$ Institute of Physical Education and Sport Science, Juhász Gyula Faculty of Education, University of Szeged, Szeged, Hungary

${ }^{5}$ Department of Pharmacology and Pharmacotherapy, Faculty of Medicine, University of Debrecen, Debrecen, Hungary

\section{Corresponding author:}

Anikó Pósa, Department of Physiology, Anatomy and Neuroscience, Faculty of Science and Informatics, University of Szeged, Kozep fasor 52, Szeged, H-6726, Hungary.

Email: paniko@bio.u-szeged.hu 
of the neutrophil proliferation/infiltration and severity of inflammation. ${ }^{4}$

It has been reported that heme oxygenase (HO) plays a central role in oxidative stress and inflammatory processes. The upregulation of the HO enzyme pathway has significant antioxidant and antiinflammatory effects in both the circulation and tissue injury. HO enzyme system serves a vital metabolic function as the rate-limiting step in the degradation of heme to generate carbon monoxide (CO), iron and biliverdin, which is converted to bilirubin. HO-1 end products generated from heme degradation may modulate inflammation. Cumulative evidence suggests that $\mathrm{CO}$ and bilirubin have anti-proliferative and anti-inflammatory effects via downregulate the production of pro-inflammatory cytokines (e.g. IL-6, IL$1 \beta$ and TNF- $\alpha$ ) and upregulate the anti-inflammatory cytokines (e.g. IL-10). ${ }^{5,6}$ The strong interaction between $\mathrm{HO}$ enzyme and pro-inflammatory cytokines (which play a pivotal role in pathological conditions) can be major factors to promote systemic inflammation.

Natural compounds, including plant and microbial secondary metabolites, can directly influence the production of inflammatory mediators as well as the expression of transcription factors and key pro- or anti-inflammatory molecules. ${ }^{7,8}$

Ophiobolins are sesterterpenoid-type secondary metabolites, a group of pentaprenyl terpenoid compounds whose structures are derivable from geranylfarnesyl diphosphate (C 25). They are characterized by a unique structure of a tricyclic 5-8-5 ring system derived from head to tail linkages of five isoprene units. Ophiobolins are produced by some phytopathogenic fungi, mainly the members of the genus Bipolaris (Cochliobolus) ${ }^{9}$ and some species of the genera Drechslera (Pyrenophora), Aspergillus (Emericella, Neosartorya) and others. ${ }^{10}$ Ophiobolin A (OPA) was the first member of the group to be isolated and characterized in the mid-1960s. ${ }^{9}$ Ophiobolins are known to be effective phytotoxins, and a large number of studies have described the action of OPA in plants. ${ }^{11,12}$ Their effect is less known in mammals, though there are some studies also in this field, for example, the biological effects of OPA on human cancer cells ${ }^{13-15}$ and boar spermatozoa ${ }^{15}$ were described.

In our present study, we aimed to characterize OPA-mediated acute systemic changes on the inflammatory process. Thus, we tested the effect of different doses $(0.01,0.1$ and $1.0 \mathrm{mg} / \mathrm{kg})$ of OPA on inflammatory mediators (IL-6, TNF- $\alpha$, MPO activity and $\mathrm{HO}$ activity) in rat plasma. To clarify the potential cytotoxic effects of OPA, we tested it on both cardiac tissue and liver. The alanine aminotransferase (ALT) and aspartate aminotransferase (AST) markers were measured to analyse the influence of OPA on hepatotoxicity.

\section{Methods}

\section{Animals and experimental design}

All manipulations were performed in accordance with the standards of the European Community guidelines on the care and use of laboratory animals and had been approved by the Institutional Ethics Committee at the University of Szeged.

All the animals were housed in a temperaturecontrolled facility $\left(23^{\circ} \mathrm{C}\right)$ maintained on a $12 / 12 \mathrm{~h}$ of light/dark cycle with food and water provided ad libitum.

Male Wistar rats (weight: 250-350 g; Toxi-Coop Zrt., Dunakeszi, Hungary) were randomly divided into four groups: $5 \%$ ethanol vehicle control $(n=18)$, $0.01 \mathrm{mg} / \mathrm{kg}$ OPA $(n=18), 0.1 \mathrm{mg} / \mathrm{kg} \mathrm{OPA}(n=18)$ and $1.0 \mathrm{mg} / \mathrm{kg}$ OPA $(n=18)$.

Twenty-four hours after vehicle (once, $1.0 \mathrm{~mL}$ of $5 \%$ ethanol, p.o.) or OPA (once, $0.01 \mathrm{mg} / \mathrm{kg}, 0.1 \mathrm{mg} /$ $\mathrm{kg}$ or $1.0 \mathrm{mg} / \mathrm{kg}$ in $1.0 \mathrm{~mL}$ of $5 \%$ ethanol, per os [p.o.]) treatment, the animals were killed and blood sample as well as the cardiac left ventricle (LV) was collected for analyses.

\section{Measurement of plasma and cardiac LV IL-6 and TNF- $\alpha$ concentrations}

Plasma samples were centrifuged at $2000 \times g_{\max }$ for $20 \mathrm{~min}$ at $4^{\circ} \mathrm{C}$. The cardiac LV samples were homogenized (Ultra-Turrax T25, IKA-Labortechnik, $2 \times$ $10 \mathrm{~s}$ on ice) in $2 \mathrm{~mL}$ modified Greenburger buffer (300 $\mathrm{mM}$ sodium chloride, $15 \mathrm{mM}$ TRIS, $2 \mathrm{mM}$ magnesium chloride $\left(\mathrm{MgCl}_{2}\right), 2 \mathrm{mM}$ Triton X-100, 0.2 $\mathrm{mM}$ phenylmethanesulfonyl fluoride, $100 \mathrm{ng} / \mathrm{mL}$ leupeptin, $100 \mathrm{ng} / \mathrm{mL}$ aprotinin, $10 \mathrm{mg} / \mathrm{L}$ trypsin inhibitor and $100 \mathrm{ng} / \mathrm{mL}$ pepstatin-A). Tissue homogenates were sonicated for $10 \mathrm{~s}$ and centrifuged at $15000 \times g$ for $15 \mathrm{~min}$. The plasma and cardiac IL- 6 and TNF- $\alpha$ levels were determined by means of quantitative enzyme-linked immunosorbent assays (ELISA) according to the manufacturer's instructions (Quantikine rat IL-6 and TNF-alpha Elisa kit; R\&D Systems, Minneapolis, Minnesota, USA). Optical density was 
measured at $450 \mathrm{~nm}$ (Benchmark Microplate Reader; Bio-Rad, Budapest, Hungary). Plasma IL-6 and TNF$\alpha$ were expressed as pictogram per millilitre plasma and cardiac values were defined as pictogram per milligram protein.

\section{Plasma and cardiac LV MPO activity}

Plasma samples were centrifuged at $2000 \times g_{\max }$ for $20 \mathrm{~min}$ at $4^{\circ} \mathrm{C}$. The cardiac LV tissues were homogenized twice for 30-30 s (Ultra Turrax T25, $13500 \mathrm{r}$ / min) in ice-cold phosphate buffer ( $50 \mathrm{mM}, \mathrm{pH} 6.0)$, freeze-thawed three times and then centrifuged $\left(15,000 \times g\right.$ for $20 \mathrm{~min}$ at $\left.4^{\circ} \mathrm{C}\right)$. A $12-\mu \mathrm{L}$ aliquot of the plasma or cardiac supernatant was mixed with $280 \mu \mathrm{L}$ of phosphate buffer ( $50 \mathrm{mM}, \mathrm{pH} 6)$ containing $0.167 \mathrm{mg} / \mathrm{mL}$ of O-dianisidine dihydrochloride, and the reaction was started with $10 \mu \mathrm{L}$ of $0.03 \%$ hydrogen peroxide and assayed spectrophotometrically at $490 \mathrm{~nm}$ (Benchmark Microplate Reader; Bio-Rad) after $90 \mathrm{~s}$ of shaking. Plasma MPO activity was expressed as milliunit per millilitre plasma and cardiac values were expressed as milliunit per milligram protein.

\section{Plasma and cardiac LV HO activity}

Plasma samples were centrifuged at $2000 \times$ g for 20 $\min$ at $4^{\circ} \mathrm{C}$. The cardiac LV tissues were homogenized (Ultra Turrax T25; $13500 \mathrm{r} / \mathrm{min} ; 2 \times 30 \mathrm{~s}$ ) in ice-cold $10 \mathrm{mM} \mathrm{N}$-2-hydroxyethylpiperazine-2ethanesulfonic acid, $32 \mathrm{mM}$ sucrose, $1 \mathrm{mM}$ dithiotreitol, $0.1 \mathrm{mM}$ ethylene diaminetetraacetic acid disodium salt dihydrate, $10 \mu \mathrm{g} / \mathrm{mL}$ trypsin inhibitor, 10 $\mu \mathrm{g} / \mathrm{mL}$ leupeptin and $2 \mu \mathrm{g} / \mathrm{mL}$ aprotinin, at $\mathrm{pH} 7.4$. The cardiac supernatant was collected by centrifugation at $15,000 \times \mathrm{g}$ for $20 \mathrm{~min}$ at $4^{\circ} \mathrm{C}$. The reaction mixture contained the following components in a final volume of $1.5 \mathrm{~mL}$ : $2 \mathrm{mM}$ glucose-6-phosphate, 0.14 $\mathrm{U} / \mathrm{mL}$ glucose-6-phosphate dehydrogenase, $15 \mu \mathrm{M}$ hemin, $120 \mu \mathrm{g} / \mathrm{mL}$ rat liver cytosol (as a source of biliverdin reductase), $2 \mathrm{mM} \mathrm{MgCl} 2 \times 6 \mathrm{H}_{2} \mathrm{O}, 100$ $\mathrm{mM} \mathrm{KH}_{2} \mathrm{PO}_{4}$ and $150 \mu \mathrm{L}$ of plasma or cardiac LV supernatant. To start the reaction, $100 \mu \mathrm{L}$ reduced form of nicotinamide adenine dinucleotide phosphate $(150 \mu \mathrm{M})$ was added to the samples and they were then incubated in the dark at $37^{\circ} \mathrm{C}$ for $60 \mathrm{~min}$. The reaction was stopped by placing the samples on ice. The bilirubin formed was calculated from the difference between the optical densities obtained at 464 and $530 \mathrm{~nm}$. Bilirubin solution was used as standard $(58.47 \mu \mathrm{g} / \mathrm{mL} ; 10 \mu \mathrm{M})$. One unit of HO activity was defined as the amount of bilirubin (nM) produced per hour per millilitre plasma or the amount of bilirubin $(\mathrm{nM})$ produced hour per milligram protein.

\section{Determination of serum ALT and AST}

Serum samples were centrifuged in $2000 \times \mathrm{g}$ for 20 min at $4^{\circ} \mathrm{C}$. Serum levels of ALT and AST were determined by ELISA according to the manufacturer's instructions (SunRed Biotechnology, Shanghai, China) and were expressed as pictogram per millilitre serum.

\section{Determination of protein concentration}

Using a commercial protein assay kit (Bio-Rad), aliquots $(20 \mu \mathrm{L})$ of the diluted samples $(15 \times$ or $25 \times$ with distilled water) were mixed with $980 \mu \mathrm{L}$ of distilled water with $200 \mu \mathrm{L}$ Bradford reagent added to each sample. After mixing and following 10 min incubation, the samples were assayed spectrophotometrically at $595 \mathrm{~nm}$. Protein level was expressed as milligram protein per millilitre.

\section{OPA purification}

OPA was purified by a multistep high-performance liquid chromatography (HPLC) purification process after an ethyl acetate extraction of the culture supernatant of Bipolaris oryzae SZMC 13003 strain according to the description of Bencsik et al. (http:// www.mdpi.com/2072-6651/6/9/2857). Briefly, the concentrated organic phase was first loaded onto an ECO 15/450V3 K glass column (YMC, Germany) filled with Kieselgel 60 (Merck, Hungary) using ethyl acetate/hexane $(5: 5, \mathrm{~V} / \mathrm{V}, 2 \mathrm{~mL} / \mathrm{min})$ as mobile phase, and the OPA contained fractions were pooled and injected onto a reverse-phase Serva ODS $(10 \times 450$ $\mathrm{mm}, 5 \mu \mathrm{m})$ HPLC column with water/acetonitrile $(3: 7, \mathrm{~V} / \mathrm{V}, 3 \mathrm{~mL} / \mathrm{min})$ eluent system to achieve OPA with the purity of up to $96 \%$. During the purification procedure, the identification, quantitation and purity of OPA were tested by analytical HPLC measurements at a wavelength of $230 \mathrm{~nm}$.

\section{Statistical analysis}

All data are presented as means \pm standard error of mean. Statistical difference between two groups was analysed with the two-tailed Student's $t$-test. $p$ Values less than 0.05 were considered significant. 


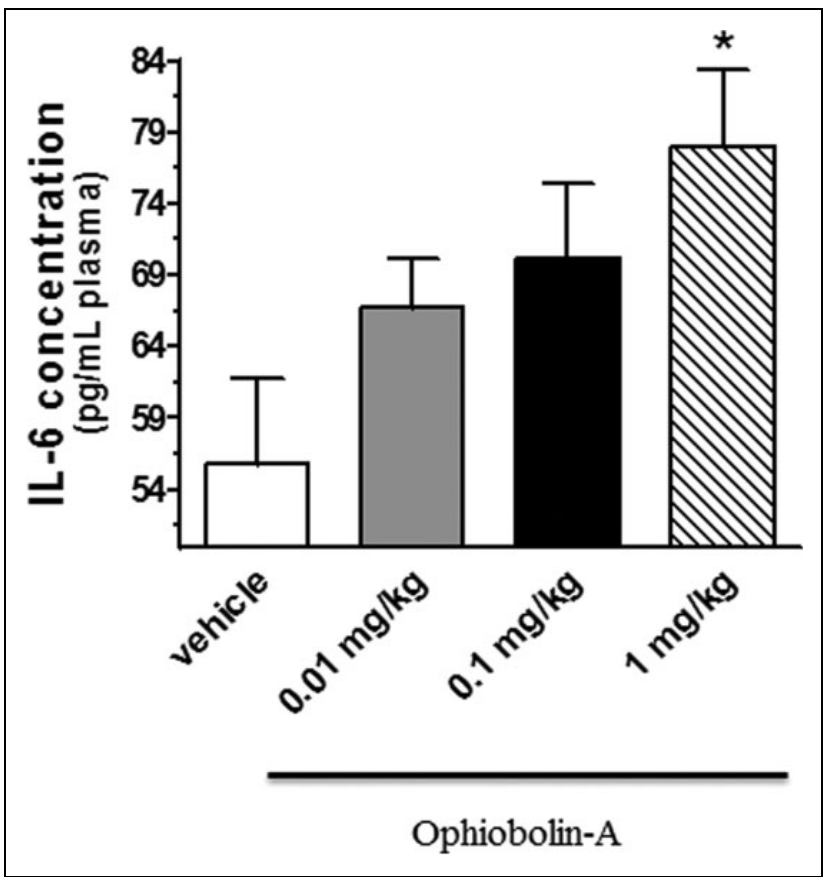

Figure I. The concentrations of plasma IL-6 (expressed as $\mathrm{Pg} / \mathrm{mL}$ plasma) after $24 \mathrm{~h}$ of treatment with $0.0 \mathrm{I}, 0 . \mathrm{I}$ and I $\mathrm{mg} / \mathrm{kg}$ OPA. Data are means \pm SEM, $n=5$. Statistical significance: ${ }^{*} p<0.05$ relative to the vehicle control group. OPA: ophiobolin A; IL-6: interleukin-6; SEM: standard error of mean.

\section{Results}

\section{Plasma IL-6 and TNF- $\alpha$ concentrations}

The plasma level of IL- 6 was increased after treatment with OPA. The administration of $1.0 \mathrm{mg} / \mathrm{kg}$ of OPA led to a significant increase compared to the vehicle control group $(55.8 \pm 5.97$ vs. $77.9 \pm 5.51 \mathrm{pg} / \mathrm{mL}$ plasma, $* p<0.05)$. Data are presented in Figure 1.

Similarly to the IL- 6 values, the TNF- $\alpha$ level reached the highest concentration at $1 \mathrm{mg} / \mathrm{kg}$ OPA and showed a significant difference compared to the vehicle control $\left(5.59 \pm 0.55\right.$ vs. $7.41 \pm 0.57 \mathrm{pg} / \mathrm{mL}$ plasma, $\left.{ }^{*} p<0.05\right)$ and to $0.1 \mathrm{mg} / \mathrm{kg}$ OPA-treated $(5.82 \pm 0.26 \mathrm{pg} / \mathrm{mL}$ plasma, $\left.p^{+}<0.05\right)$ groups. Data are shown in Figure 2.

\section{Plasma MPO and $\mathrm{HO}$ enzyme activity}

The increasing doses of OPA caused a dosedependent elevation in plasma MPO activity in each group compared to the vehicle control animals (vehicle control: $45.3 \pm 2.04 \mathrm{mU} / \mathrm{mL}$ plasma, ${ }^{*} p<0.05$; $0.01 \mathrm{mg} / \mathrm{kg}$ OPA: $53.3 \pm 2.86 \mathrm{mU} / \mathrm{mL}$ plasma, ${ }^{*} p<$ $0.05 ; 0.1 \mathrm{mg} / \mathrm{kg}$ OPA: $56.9 \pm 2.22 \mathrm{mU} / \mathrm{mL}$ plasma, $* * p<0.01$ and $1.0 \mathrm{mg} / \mathrm{kg}$ OPA: $59.2 \pm 2.5 \mathrm{mU} / \mathrm{mL}$ plasma, $* * p<0.01)$. Data are shown in Figure 3.

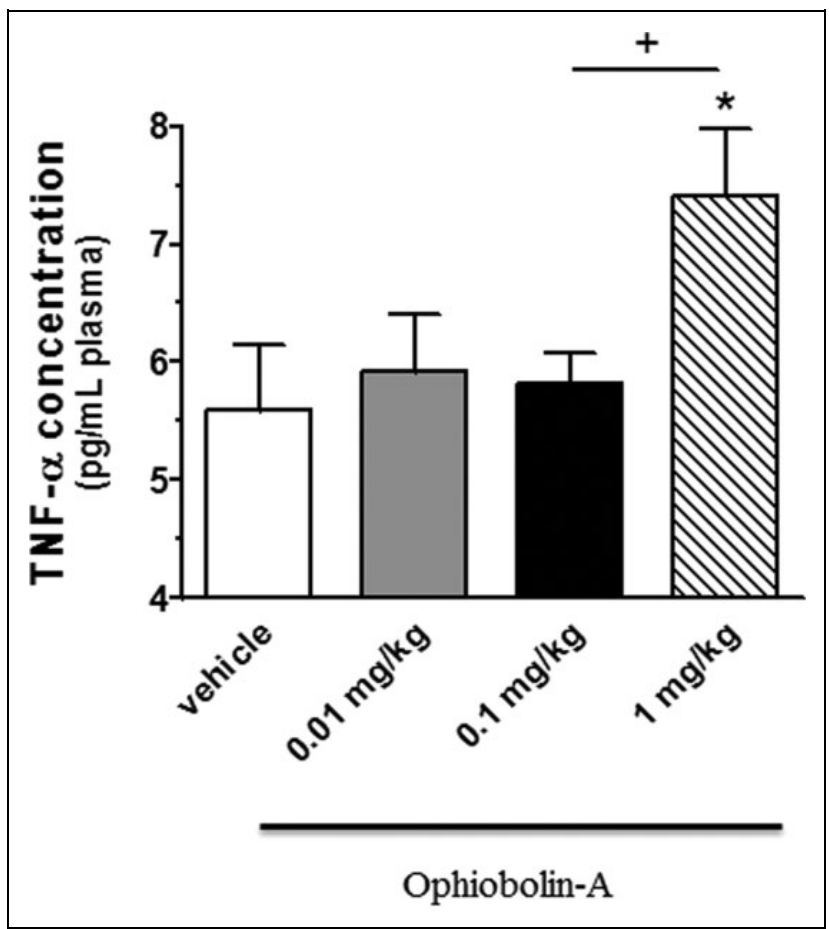

Figure 2. The plasma levels of TNF- $\alpha$ (expressed as $\mathrm{pg} / \mathrm{mL}$ plasma) in vehicle control and OPA-treated groups. Data are means \pm SEM, $n=6-9$. Statistical significance: ${ }^{*} p<$ 0.05 relative to the vehicle control group; ${ }^{+} p<0.05$ a significant difference between animals treated with 0.1 and I mg/kg OPA. TNF- $\alpha$ : tumour necrosis factor-alpha; OPA: ophiobolin A; SEM: standard error of mean.

After $24 \mathrm{~h}$ of treatment with $1.0 \mathrm{mg} / \mathrm{kg}$ OPA, we observed a significant decrease in $\mathrm{HO}$ enzyme activity compared to the vehicle control group (74.1 \pm 9.03 vs. $48.3 \pm 1.77 \mathrm{nM}$ bilirubin $/ \mathrm{h} / \mathrm{mL}$ plasma, ${ }^{*} p$ $<0.05)$. In addition, we also observed significant differences between $1.0 \mathrm{mg} / \mathrm{kg}$ and lower dose OPAtreated groups $(0.1 \mathrm{mg} / \mathrm{kg}$ OPA: $55.8 \pm 1.42 \mathrm{nM}$ bilirubin $/ \mathrm{h} / \mathrm{mL}$ plasma, ${ }^{+} p<0.05$ and $0.01 \mathrm{mg} / \mathrm{kg}$ OPA: $63.4 \mathrm{nM}$ bilirubin $/ \mathrm{h} / \mathrm{mL}$ plasma, ${ }^{\text {aa }} p<0.01$ ). Data are shown in Figure 4.

\section{Cardiac LV IL-6 and TNF- $\alpha$ concentrations}

As shown in Figures 5 and 6, OPA treatment did not cause significant changes in IL- 6 and TNF- $\alpha$ concentrations in cardiac LV.

\section{Cardiac LV MPO and HO activity}

The results show that administration of OPA did not produce changes in the activity of MPO and HO enzymes in cardiac LV. Data are shown in Figures 7 and 8 . 


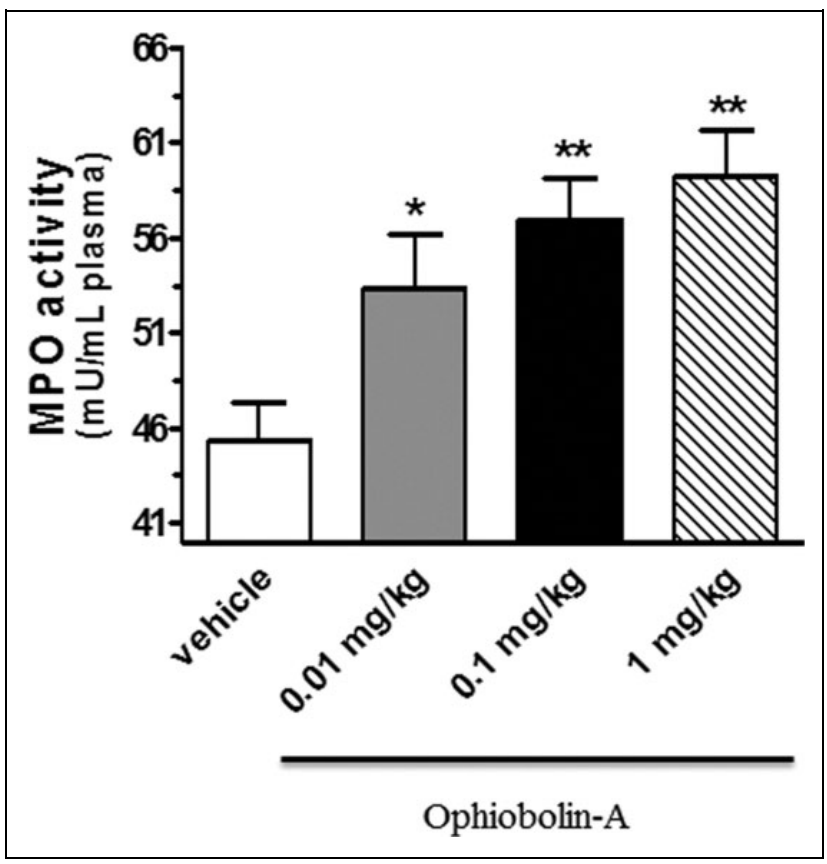

Figure 3. Changes in plasma MPO activity (expressed as $\mathrm{mU} / \mathrm{mL}$ plasma) after $24 \mathrm{~h}$ of OPA treatment. Data are means \pm SEM, $n=7-9$. Statistical significance: ${ }^{*} p<0.05$ and ${ }^{* *} p<0.0$ I relative to the vehicle control group. MOP: myeloperoxidase; OPA: ophiobolin A; SEM: standard error of mean.

\section{Serum ALT and AST concentrations}

No differences in serum ALT and AST concentrations in response to increasing doses of OPA were observed between vehicle control and OPA-treated animals. Data are shown in Figures 9 and 10.

\section{Discussion}

Recently, much interest has been generated for a wide range of compounds from microbial sources with reports demonstrating their role in the modulation of inflammatory responses. Among these, several microbial metabolites show potent anti-inflammatory action; ${ }^{16}$ some derivatives contribute to chronic inflammation and inflammatory diseases.

The aim of our study was to clarify the effects of OPA, a phytotoxic sesterterpenoid of fungal origin, on the modulation of pro-inflammatory cytokines such as IL- 6 and TNF- $\alpha$. Furthermore, its effect on the inflammatory biomarker MPO activity as well as on the activation of $\mathrm{HO}$ was also investigated.

In the current investigation, OPA was shown to promote the inflammatory processes. We demonstrated that administrations of $1.0 \mathrm{mg} / \mathrm{kg}$ of OPA led

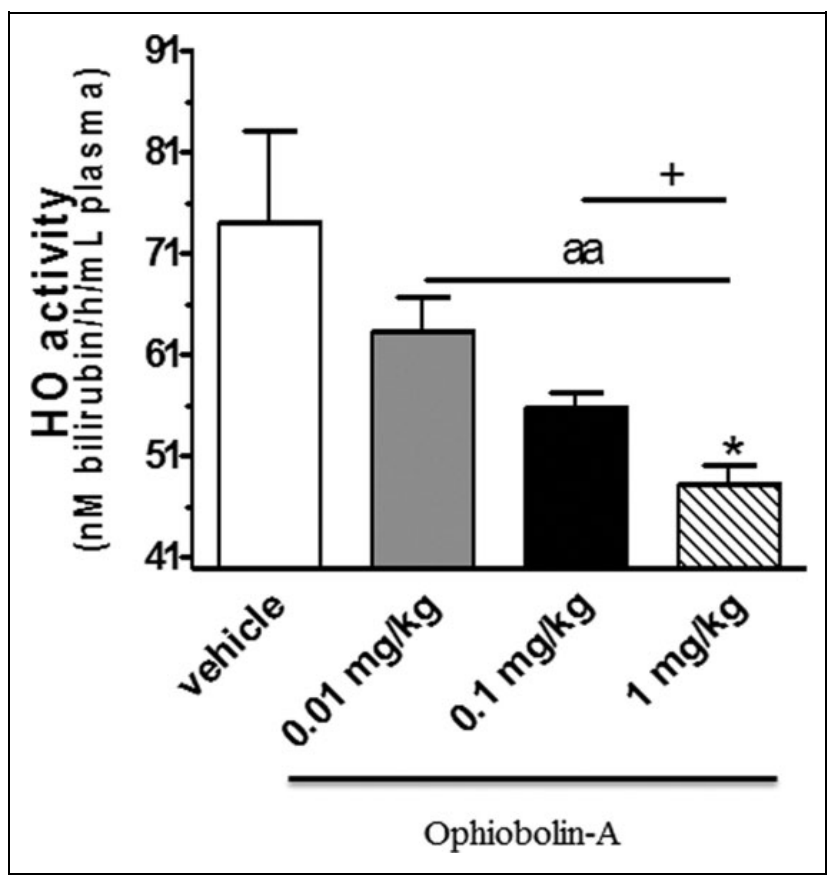

Figure 4. Effects of OPA treatment on plasma level of $\mathrm{HO}$ activity (expressed as $\mathrm{nM}$ bilirubin/h/mL plasma) after $24 \mathrm{~h}$. Data are means \pm SEM, $n=6-7$. Statistical significance: ${ }^{*} p<$ 0.05 relative to the vehicle control group; ${ }^{+} p<0.05$ a significant difference between animals treated with 0.1 and 1.0 $\mathrm{mg} / \mathrm{kg}$ OPA; ${ }^{\text {aa }} \mathrm{p}<0.0 \mathrm{l}$ a significant difference between animals treated with 0.01 and $1.0 \mathrm{mg} / \mathrm{kg}$ OPA. OPA: ophiobolin $\mathrm{A}$; HO: heme oxygenase; SEM: standard error of mean.

to significant increases in the plasma levels of IL-6. Similarly to the IL- 6 , the TNF- $\alpha$ level reached the highest concentration at $1 \mathrm{mg} / \mathrm{kg}$ OPA. All these inflammatory cytokines play a critical role in controlling many inflammatory responses. ${ }^{17}$ In a previous study, Nagashima et al. observed elevation of serum IL-6 level in 24-h rubratoxin B-treated mouse model. ${ }^{18}$ Dugyala et al. found that TNF- $\alpha$ plays a role in the mechanism of fumonisin B toxicity. ${ }^{19}$ Gene expression of inflammatory cytokine leads to another stage of the inflammatory cascade and facilitates the recruitment of effector cells such as monocytes and neutrophils to the site of disturbance. Neutrophils create a cytotoxic environment by releasing noxious chemicals. MPO is a hemoprotein that is stored in azurophilic granules of polymorphonuclear neutrophils and macrophages. MPO catalyses the conversion of chloride and hydrogen peroxide to hypochlorite and is secreted during inflammatory condition. ${ }^{20}$ The elevated MPO concentrations of both plasma and tissue have been used as a marker of polymorphonuclear leukocytosis in sepsis and inflammation..$^{21-23}$ Our results show that a single treatment with increasing doses of 


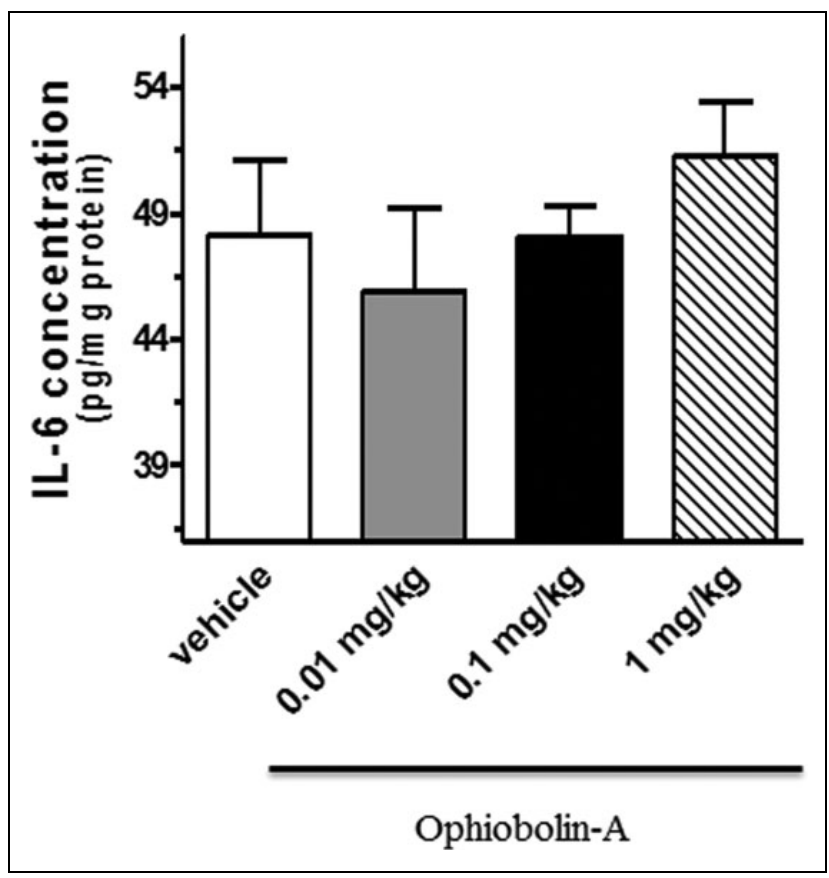

Figure 5. The concentrations of IL-6 (expressed as pg/mg protein) in the cardiac LV after $24 \mathrm{~h}$ of treatment with $0.0 \mathrm{l}$, 0.1 and $1.0 \mathrm{mg} / \mathrm{kg}$ OPA. Data are means \pm SEM, $n=6-8$. LV: left ventricle; OPA: ophiobolin A; IL-6: interleukin-6; SEM: standard error of mean.

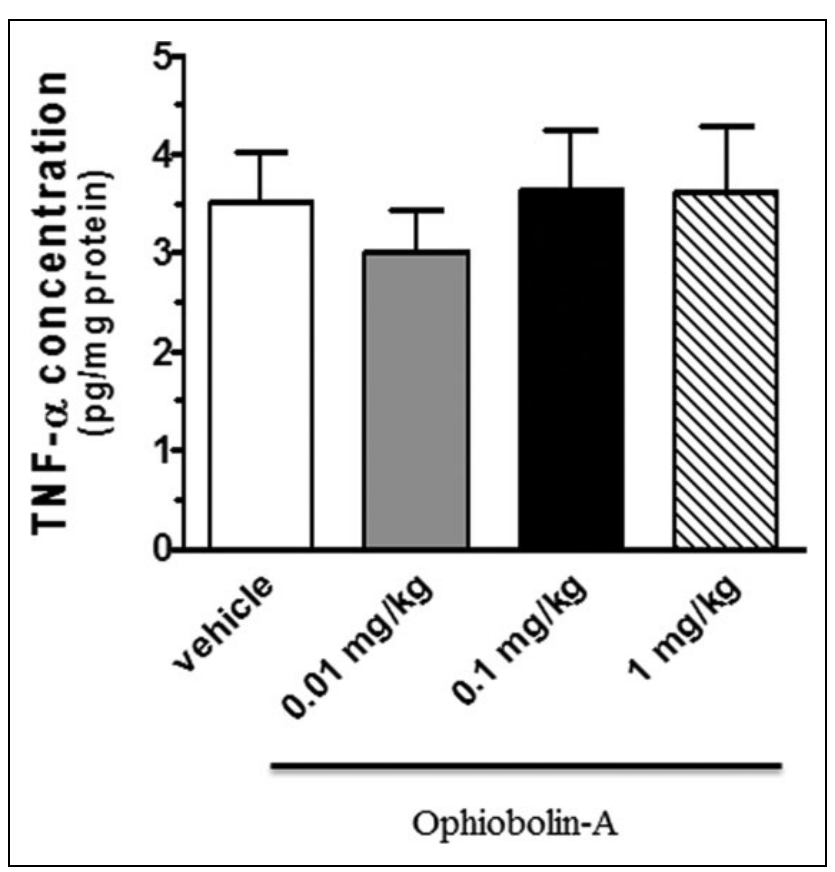

Figure 6. The levels of TNF- $\alpha$ (expressed as pg/mg protein) in the cardiac LV of vehicle control and OPA-treated animals. Data are means \pm SEM, $n=6-8$. OPA: ophiobolin A; TNF- $\alpha$ : tumour necrosis factor-alpha; LV: left ventricle; SEM: standard error of mean.

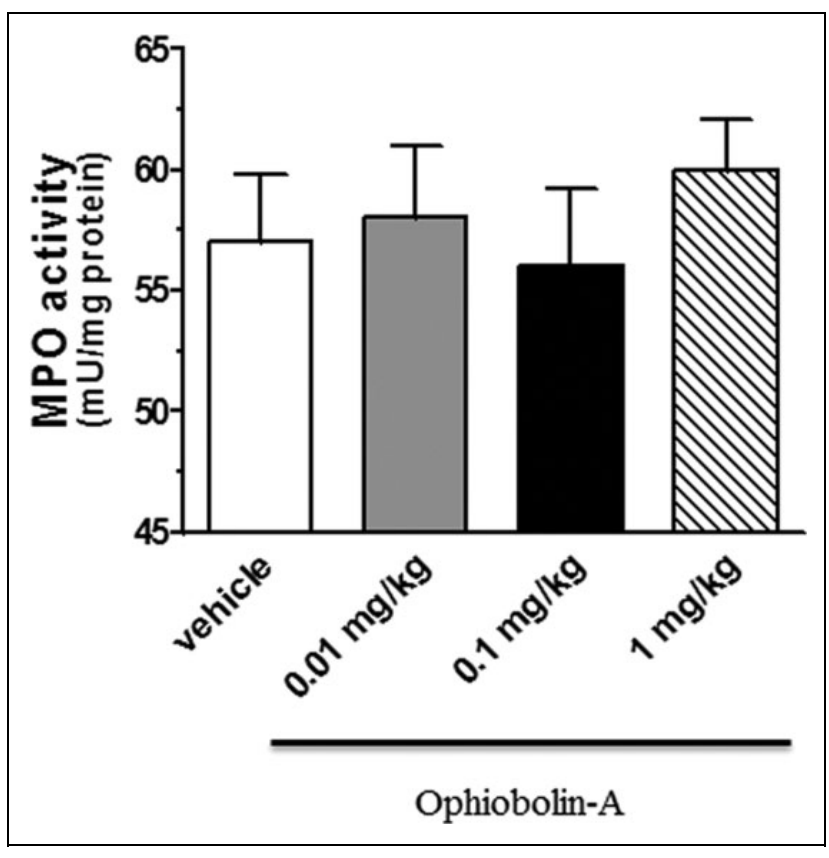

Figure 7. MPO activity (expressed as $\mathrm{mU} / \mathrm{mg}$ protein) in the cardiac LV of vehicle control and OPA-treated animals. Data are means \pm SEM, $n=7-8$. OPA: ophiobolin A; LV: left ventricle; MPO: myeloperoxidase; SEM: standard error of mean.

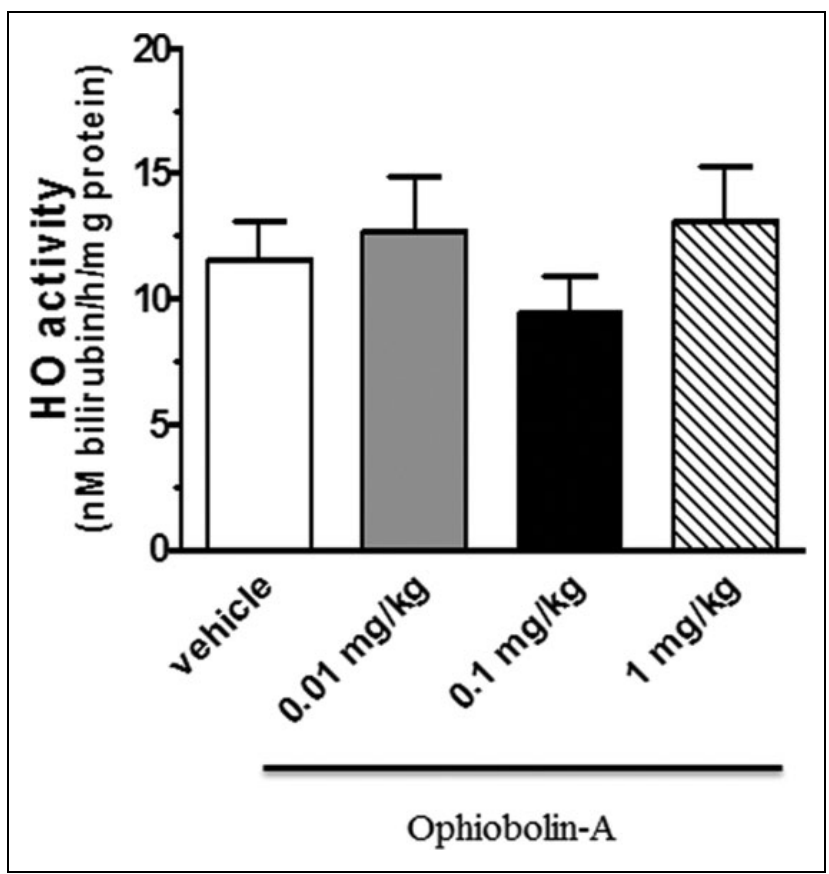

Figure 8. HO activity (expressed as $n M$ bilirubin $/ \mathrm{h} / \mathrm{mg}$ protein) in the cardiac LV of vehicle control and OPAtreated animals. Data are means \pm SEM, $n=7$. OPA: ophiobolin A; LV: left ventricle; HO: heme oxygenase; SEM: standard error of mean. 


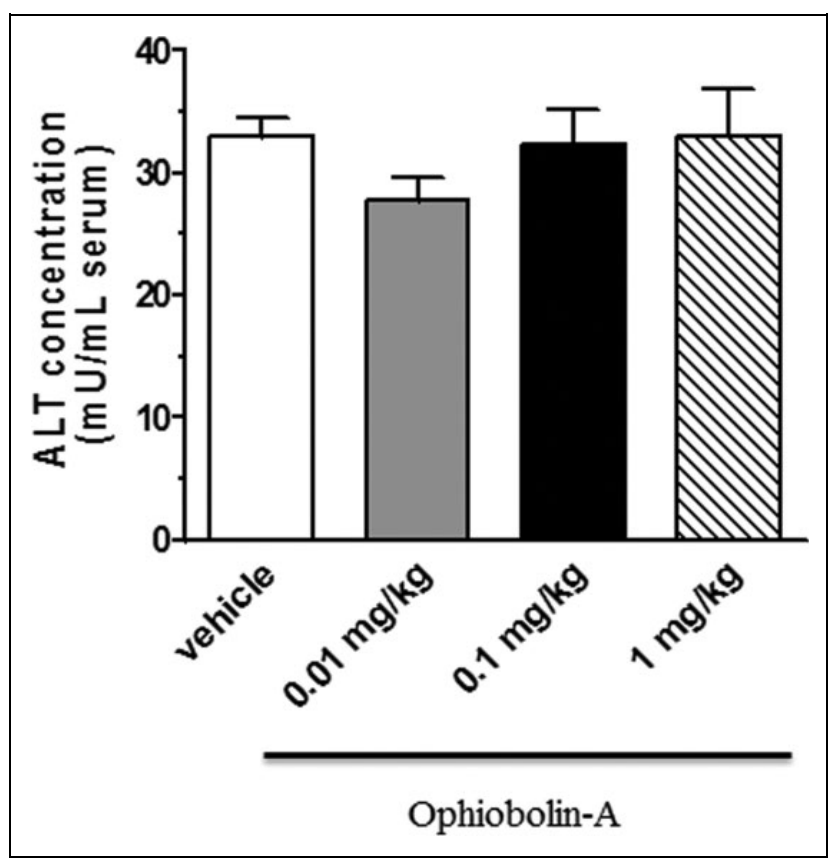

Figure 9. The concentrations of serum ALT (expressed as $\mathrm{mU} / \mathrm{mL}$ serum) in vehicle control and OPA-treated groups. Data are means \pm SEM, $n=11-12$. ALT: alanine aminotransferase; OPA: ophiobolin A; SEM: standard error of mean.

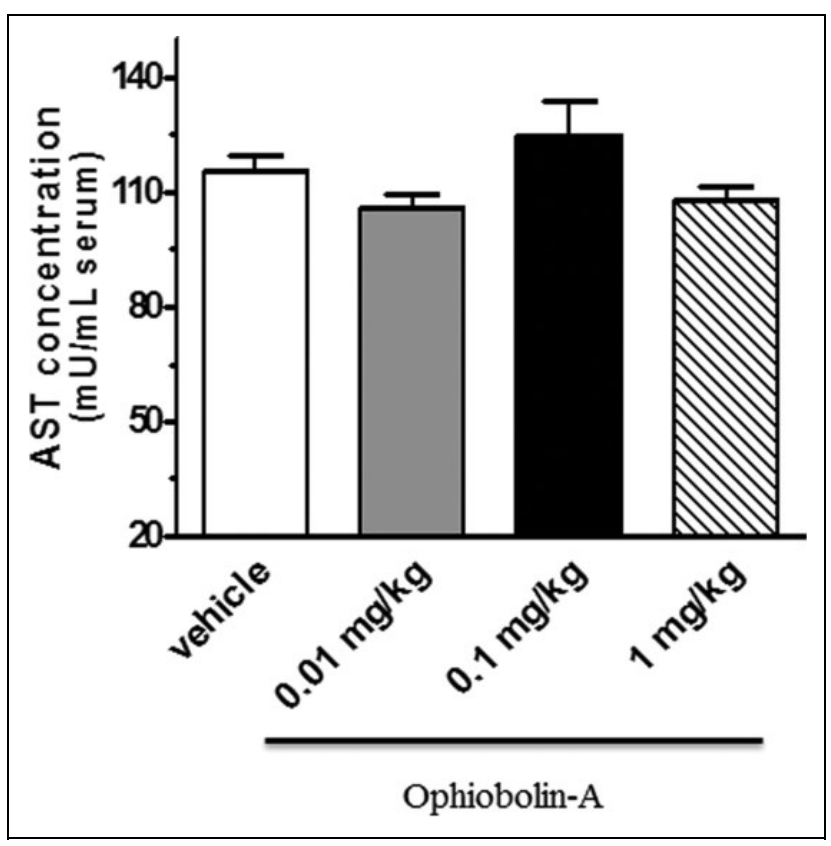

Figure 10. The levels of serum AST (expressed as $\mathrm{mU} / \mathrm{mL}$ serum) in vehicle control and OPA-treated groups. Data are means \pm SEM, $n=5-12$. AST: aspartate aminotransferase; OPA: ophiobolin A; SEM: standard error of mean.

OPA caused a dose-dependent increase in the plasma. The administration of $1 \mathrm{mg} / \mathrm{kg}$ OPA induced $75 \%$ increase in the MPO activity. MPO is linked to both inflammation and oxidative stress by catalysing the formation of oxidizing agents.

It has been reported that HO plays a central role in regulating the levels of intracellular heme by catalysing the oxidative degradation of heme and by generating $\mathrm{CO}$, biliverdin and bilirubin. ${ }^{24}$ Three isoforms of $\mathrm{HO}$ have been described: an inducible isoform, HO-1 and two constitutively expressed isoforms, HO-2 and HO-3. In animal and human studies, HO-1 may affect many pathways and cytokines. During physiological processes, HO activity plays a role in the inhibition of apoptosis and oxidative processes, with significant reductions in inflammatory events including production of inflammatory cytokines. HO-1 and its products such as $\mathrm{CO}$, biliverdin/ bilirubin and free iron may modulate inflammation. ${ }^{24} \mathrm{CO}$ can downregulate the production of pro-inflammatory cytokines (e.g. IL-1 $\beta$, IL-6 and TNF- $\alpha$ ). These effects were attributed to alterations of mitogen-activated protein kinase (MAPK) activities, including p38 MAPK and c-Jun kinase. ${ }^{25,26}$ Furthermore, HO-1/CO activation downregulates the inflammatory response by blocking the release of NO from inducible nitrogen monoxide synthase and expression of the granulocyte macrophage colony-stimulating factor from macrophages and smooth muscle cells. ${ }^{27}$ Jung et al. reported that $\mathrm{CO}$ can modulate the activation of the NLRP3 inflammasome, which regulates the production of proinflammatory cytokines. ${ }^{28}$ Devey et al. demonstrated that HO- 1 inhibits the production of TNF- $\alpha$ and IL- 6 in the liver. ${ }^{29}$ In another model, Kapturczak et al. showed that HO-1 deficiency leads to increased production of pro-inflammatory cytokines. ${ }^{30}$ Our data indicate that treatment with the fungal phytotoxin, OPA, increased the concentrations of IL- 6 , TNF- $\alpha$ and MPO inflammatory mediators in blood plasma. The plasma $\mathrm{HO}$ activity showed a significant reduction $24 \mathrm{~h}$ after administrations of OPA. In agreement with previous observations, our results show that systemic inflammation suppresses the level of HO.

Elevated circulating concentrations of proinflammatory cytokines and adhesion molecules suggest that inflammatory processes are occurring systemically and play a role in the development of inflammatory disorders, including allergic reactions, arthritis, cancer, atherosclerosis and ischemic heart disease. ${ }^{31,32}$ Although, many studies have detected a positive correlation between inflammation and cardiovascular diseases in different models, we did not observe inflammation-related changes in cardiac tissue after $24 \mathrm{~h}$ of acute OPA administrations. Animal 
studies on TNF- $\alpha$ and development of atherosclerosis have produced mixed results. Inhibition of TNF- $\alpha$ in apoE-deficient mice resulted in significant decrease of atheromatous lesions ${ }^{33}$ in wild-type animals, it produced no improvements. ${ }^{34}$ In another inflammationrelated disease model, Bury et al. revealed that this fungal metabolite, OPA, displays in vivo antitumor activity in mammalian. ${ }^{35}$

Since we obtained that OPA treatment led to systemic inflammatory changes measured in plasma, our aim was to clarify if there is any potential toxic effect of OPA on both liver and cardiac tissue. In addition to inflammatory changes, we found a significant $\mathrm{HO}$ activity reduction in plasma. The decrease in circulating $\mathrm{HO}$ enzyme activity promotes oxidative processes which can trigger hepatic damage and modulate pathways that control normal biological functions. ${ }^{36,37}$

To analyse the potential hepatotoxic effects of OPA, ALT and AST markers were also measured. It has been demonstrated that a great number of toxins, microbial metabolites and natural products could cause liver damage. Transaminases are located in liver cells and leak out into the circulation when liver cells are injured. Ozer et al. reported that serum/ plasma ALT and AST biomarkers in humans and rats have potential to be utilized as bridging markers to monitor liver injury in early clinical trials. The ALT is a more specific indicator of liver inflammation than AST, which is also found in the heart and skeletal muscle. ${ }^{38}$ Hepatic dysfunction accompanied by elevated ALT and AST levels show a complex relationship with cardiac diseases. ${ }^{39}$ In our study, we did not observed changes in the serum ALT and AST concentrations after $24 \mathrm{~h}$ of treatment with $0.01,0.1$ and 1 $\mathrm{mg} / \mathrm{kg}$ OPA.

In summary, the current report highlights the acute role of OPA in systemic and cardiac-specific inflammatory responses. While the inflammation-inducing effects mediated by OPA in the plasma seem related to the activation of inflammatory markers (e.g. IL-6, TNF- $\alpha$ and MPO) and the suppression of HO enzyme, in the cardiac tissue, OPA treatment did not cause changes in the inflammatory responses. Furthermore, OPA did not show cytotoxic effects in the serum ALT and AST levels.

\section{Authors' contribution}

All authors participated in the design and interpretation of the studies, in the analysis of the data and in the drafting and final approval of the article. Renáta Szabó and Anikó Pósa contributed equally to this article as first authors.

\section{Acknowledgements}

This research was realized in the frames of TÁMOP 4.2.2.A-11/1/KNOV-2012-0035, AGR_PIAC_13-1-20130008, DE-KUTEGY and TÁMOP 4.2.4. A/2-11-1-20120001 "National Excellence Program: Elaborating and Operating an Inland Student and Researcher Personal Support System." The project was subsidized by the European Union and cofinanced by the European Social Fund. This work was connected to the project GINOP-2.3.3-152016-00006.

\section{Declaration of Conflicting Interests}

The author(s) declared no potential conflicts of interest with respect to the research, authorship, and/or publication of this article.

\section{Funding}

The author(s) received no financial support for the research, authorship, and/or publication of this article.

\section{References}

1. Nathan C. Points of control in inflammation. Nature 2002; 420: 846-852.

2. Dinarello CA. Proinflammatory cytokines. Chest 2000; 118: 503-508.

3. Faith M, Sukumaran A, Pulimood AB, et al. How reliable an indicator of inflammation is myeloperoxidase activity? Clin Chim Acta 2008; 396: 23-25.

4. Kothari N, Keshari RS, Bogra J, et al. Increased myeloperoxidase enzyme activity in plasma is an indicator of inflammation and onset of sepsis. $J$ Crit Care 2011; 26: 435 e1-435 e7.

5. Blancou P, Tardif V, Simon T, et al. Immunoregulatory properties of heme oxygenase-1. Methods $\mathrm{Mol}$ Biol 2011; 677: 247-268.

6. Simon T, Anegon I and Blancou P. Heme oxygenase and carbon monoxide as an immunotherapeutic approach in transplantation and cancer. Immunotherapy 2011; 3: 15-18.

7. Apetz N, Munch G, Govindaraghavan S, et al. Natural compounds and plant extracts as therapeutics against chronic inflammation in Alzheimer's disease-a translational perspective. CNS Neurol Disord Drug Targets 2014; 13: 1175-1191.

8. Rogerio AP, Sa-Nunes A and Faccioli LH. The activity of medicinal plants and secondary metabolites on eosinophilic inflammation. Pharmacol Res 2010; 62: 298-307.

9. Au TK, Chick WS and Leung PC. The biology of ophiobolins. Life Sci 2000; 67: 733-742.

10. Liu Y, Wang L, Jung JH, et al. Sesterterpenoids. Nat Prod Rep 2007; 24: 1401-1429. 
11. Evidente A, Andolfi A, Cimmino A, et al. Herbicidal potential of ophiobolins produced by Drechslera gigantea. J Agr Food Chem 2006; 54: 1779-1783.

12. Leung PC, Taylor WA, Wang JH, et al. Ophiobolin A. A natural product inhibitor of calmodulin. $J$ Biol Chem 1984; 259: 2742-2747.

13. Bury M, Girault A, Megalizzi V, et al. Ophiobolin A induces paraptosis-like cell death in human glioblastoma cells by decreasing BKCa channel activity. Cell Death Dis 2013; 4: e561.

14. Fujiwara H, Matsunaga K, Kumagai H, et al. Ophiobolin A, a novel apoptosis-inducing agent from fungus strain f-7438. Pharm Pharmacol Commun 2000; 6: 427-431.

15. Bencsik O, Papp T, Berta M, et al. Ophiobolin A from Bipolaris oryzae perturbs motility and membrane integrities of porcine sperm and induces cell death on mammalian somatic cell lines. Toxins 2014; 6: 2857-2871.

16. Brower V.Back to nature: Extinction of medicinal plants threatens drug discovery. J Natl Cancer Inst 2008; 100: 838-839.

17. Ghosh S and Karin M. Missing pieces in the NF-kappaB puzzle. Cell 2002; 109: S81-S96.

18. Nagashima H, Nakamura $\mathrm{K}$ and Goto T. Rubratoxin B caused hypoglycemia and elevated serum interleukin-6 levels in mice. Mycotoxins 2001; 51: 7-12.

19. Dugyala RR, Sharma RP, Tsunoda M, et al. Tumor necrosis factor-alpha as a contributor in fumonisin B1 toxicity. J Pharmacol Exp Ther 1998; 285: 317-324.

20. van der Veen BS, de Winther MP and Heeringa P. Myeloperoxidase: Molecular mechanisms of action and their relevance to human health and disease. Antioxid Redox Signal 2009; 11: 2899-2937.

21. Bradley PP, Priebat DA, Christensen RD, et al. Measurement of cutaneous inflammation: Estimation of neutrophil content with an enzyme marker. $J$ Invest Dermatol 1982; 78: 206-209.

22. Posa A, Szabo R, Csonka A, et al. Endogenous estrogen-mediated heme oxygenase regulation in experimental menopause. Oxid Med Cell Longev 2015; 2015: 429713.

23. Szalai Z, Szasz A, Nagy I, et al. Anti-inflammatory effect of recreational exercise in TNBS-induced colitis in rats: Role of NOS/HO/MPO system. Oxid Med Cell Longev 2014; 2014: 925981.

24. Abraham NG and Kappas A. Pharmacological and clinical aspects of heme oxygenase. Pharmacol Rev 2008; 60: 79-127.

25. Otterbein LE, Bach FH, Alam J, et al. Carbon monoxide has anti-inflammatory effects involving the mitogen-activated protein kinase pathway. Nat Med 2000; 6: 422-428.
26. Morse D, Pischke SE, Zhou Z, et al. Suppression of inflammatory cytokine production by carbon monoxide involves the JNK pathway and AP-1. J Biol Chem 2003; 278: 36993-36998.

27. Sawle P, Foresti R, Mann BE, et al. Carbon monoxide-releasing molecules (CO-RMs) attenuate the inflammatory response elicited by lipopolysaccharide in RAW264.7 murine macrophages. $\mathrm{Br} J$ Pharmacol 2005; 145: 800-810.

28. Jung SS, Moon JS, Xu JF, et al. Carbon monoxide negatively regulates NLRP3 inflammasome activation in macrophages. Am J Physiol Lung Cell Mol Physiol 2015; 308: L1058-L1067.

29. Devey L, Ferenbach D, Mohr E, et al. Tissue-resident macrophages protect the liver from ischemia reperfusion injury via a heme oxygenase-1-dependent mechanism. Mol Ther 2009; 17: 65-72.

30. Kapturczak MH, Wasserfall C, Brusko T, et al. Heme oxygenase-1 modulates early inflammatory responses: Evidence from the heme oxygenase-1-deficient mouse. Am J Pathol 2004; 165: 1045-1053.

31. Willerson JT and Ridker PM. Inflammation as a cardiovascular risk factor. Circulation 2004; 109: II2-II10.

32. Mantovani A.Cancer: Inflammation by remote control. Nature 2005; 435: 752-753.

33. Branen L, Hovgaard L, Nitulescu M, et al. Inhibition of tumor necrosis factor-alpha reduces atherosclerosis in apolipoprotein E knockout mice. Arterioscler Thromb Vasc Biol 2004; 24: 2137-2142.

34. Schreyer SA, Vick CM and LeBoeuf RC. Loss of lymphotoxin-alpha but not tumor necrosis factoralpha reduces atherosclerosis in mice. $J$ Biol Chem 2002; 277: 12364-12368.

35. Bury M, Novo-Uzal E, Andolfi A, et al. Ophiobolin A, a sesterterpenoid fungal phytotoxin, displays higher in vitro growth-inhibitory effects in mammalian than in plant cells and displays in vivo antitumor activity. Int $J$ Oncol 2013; 43: 575-585.

36. Li S, Tan HY, Wang N, et al. The role of oxidative stress and antioxidants in liver diseases. Int $J \mathrm{Mol} \mathrm{Sci}$ 2015; 16: 26087-26124.

37. Origassa CS and Camara NO. Cytoprotective role of heme oxygenase- 1 and heme degradation derived end products in liver injury. World J Hepatol 2013; 5: 541-549.

38. Ozer J, Ratner M, Shaw M, et al. The current state of serum biomarkers of hepatotoxicity. Toxicology 2008; 245: 194-205.

39. Alvarez AM and Mukherjee D. Liver abnormalities in cardiac diseases and heart failure. Int J Angiol 2011; 20: $135-142$. 